\title{
Decision-making in international organizations: institutional design and performance
}

\author{
Thomas Sommerer $^{1}$ (D) Theresa Squatrito $^{2} \cdot$ Jonas Tallberg $^{3}$. \\ Magnus Lundgren ${ }^{4}$
}

Accepted: 19 July 2021 / Published online: 17 October 2021

(c) The Author(s) 2021

\begin{abstract}
International organizations (IOs) experience significant variation in their decisionmaking performance, or the extent to which they produce policy output. While some IOs are efficient decision-making machineries, others are plagued by deadlock. How can such variation be explained? Examining this question, the article makes three central contributions. First, we approach performance by looking at IO decision-making in terms of policy output and introduce an original measure of decision-making performance that captures annual growth rates in IO output. Second, we offer a novel theoretical explanation for decision-making performance. This account highlights the role of institutional design, pointing to how majoritarian decision rules, delegation of authority to supranational institutions, and access for transnational actors (TNAs) interact to affect decision-making. Third, we offer the first comparative assessment of the decision-making performance of IOs. While previous literature addresses single IOs, we explore decision-making across a broad spectrum of 30 IOs from 1980 to 2011. Our analysis indicates that IO decisionmaking performance varies across and within IOs. We find broad support for our theoretical account, showing the combined effect of institutional design features in shaping decision-making performance. Notably, TNA access has a positive effect on decision-making performance when pooling is greater, and delegation has a positive effect when TNA access is higher. We also find that pooling has an independent, positive effect on decision-making performance. All-in-all, these findings suggest that the institutional design of IOs matters for their decision-making performance, primarily in more complex ways than expected in earlier research.
\end{abstract}

Keywords International organizations · Institutional design · Decision-making · Global governance $\cdot$ Performance

Responsible Editor: Axel Dreher

Thomas Sommerer

thomas.sommerer@uni-potsdam.de

Extended author information available on the last page of the article 
International organizations (IOs) vary significantly in their decision-making performance, or the extent to which they produce policy output. Some IOs, such as the United Nations (UN), have principal decision-making bodies prone to deadlock and are best known for their failures to deliver. Other IOs, such as the European Union (EU), produce hundreds of decisions every year. At the same time, IOs experience variation over time in their decision-making output. Some IOs, like the Association of Southeast Asian Nations (ASEAN), have witnessed a growth in their policy output over time, while others, such as the International Monetary Fund (IMF) have had relatively stable levels of output from year to year.

How can we explain such variation in the decision-making performance of IOs? What factors make IOs efficient decision-making machineries or, alternatively, generate gridlock? Gaining a better understanding of this issue is important for both research and policy-making. Decision-making performance matters because it sheds light on IO performance more broadly. Existing research typically distinguishes between two main aspects of IO performance-process and outcome-where the first mainly entails a focus on organizational efficiency and the latter a focus on organizational goal achievement (e.g., Gutner \& Thompson 2010; Lall, 2017; Squatrito et al., 2018). In privileging decision-making performance, we focus on an intermediate step between process and outcome, namely, IOs' ability to adopt policy decisions (see also Pollack \& Hafner-Burton, 2010). IO policy output in most instances temporally precedes outcomes while also being indicative of process; without efficient processes, outputs are unlikely and without outputs, outcomes are difficult for IOs to produce. Decision-making performance, however, is not equivalent to IO performance as a whole. Rather, it is one crucial piece of the broader picture that is IO performance.

Decision-making performance also matters because it relates to regime effectiveness. Regime effectiveness refers to the extent to which international cooperation succeeds in reducing or solving societal problems (Young, 1999). While enforcing peace, reducing poverty, liberalizing trade, and preventing the spread of infectious diseases will require more than IO decision-making, arriving at decisions is a first and necessary requirement if regimes are to be effective (Gutner \& Thompson 2010; Tallberg et al., 2016a). Stated differently, gaining insights into decision-making performance constitutes an important step toward understanding how IOs contribute to the problem-solving effectiveness of regimes, a question that is increasingly relevant as IOs have grown more numerous, (Shanks et al., 1996; Pevehouse et al., 2020), gained increasing political authority (Hooghe et al., 2017; Zürn, 2018), and regime complexes have evolved (Alter \& Raustiala, 2018).

This article makes three central contributions. First, we advance a novel focus in the study of IO performance, examining decision-making performance as a component of the broader phenomenon of IO performance (Tallberg et al., 2016a). ${ }^{1}$ Our focus on decision-making to shed light on IO performance is inspired by the study

\footnotetext{
1 We define international organizations as formal intergovernmental, multilateral and bureaucratic organizational structures established to further cooperation among states (Martin and Simmons 2012; Rittberger et al., 2012; Hooghe and Marks 2015).
} 
of domestic legislative performance (e.g., Olson \& Nonidez, 1972; Arter, 2006; Damgaard \& Jensen, 2006), which conceives of performance in terms of decisionmaking capacity. Decision-making performance describes the extent to which an IO is capable of producing policy output through its main decision-making body, given pressures to address problems. To empirically capture decision-making performance, we introduce a new measure based on the annual growth rate in policy output. This measure recognizes that IOs display considerable heterogeneity in their policy output, and therefore normalizes policy output by focusing on growth curves rather than absolute numbers. This measure thereby enables a systematic analysis of variation in decision-making performance over time and across IOs with different output baselines, offering a key tool for future research on IO performance.

Second, we build on rational institutionalism to develop a theoretical account that focuses on institutional design to explain IO decision-making performance. While recent literature cast doubts on the centrality of institutional design for performance (Barnett \& Finnemore, 2004; Gray, 2018), we argue that institutional design indeed matters, but in ways more complex than previously understood (see also Lall, 2017). ${ }^{2}$ Specifically, features of institutional design affect IO decision-making performance by way of their interaction rather than independent effects. Some design features combine to enable collective decision-making by mutually reinforcing efficiency gains, such as reduced transaction costs. Other constellations of design features undermine one another to minimize their benefits to collective decisionmaking. We theorize interactions between three design features: (1) pooling - the surrender of states' decision-making veto; (2) delegation-the granting of authority to an independent supranational body; and (3) access for transnational actors (TNAs) - the granting of privileges to TNAs, such as opportunities to be present, make statements, and even vote in interstate decision-making. Pooling, delegation, and TNA access represent the most profound changes to institutional design that have occurred in recent decades, and have received much scholarly attention. We consider how the shift away from purely member-driven IOs affects the strategic setting within which states, supranational, and transnational actors exercise entrepreneurship to influence decision-making. While previous literature focuses on how individual features of institutional design shape interstate bargaining dynamics (e.g., Boehmer et al., 2004; Hawkins et al., 2006; Hansen et al., 2008; Slapin, 2008; Finke \& Bailer, 2019), we theorize how pooling, delegation, and TNA access combine to shape the effects of state, supranational, and transnational entrepreneurship on policy output by way of their net effect on cooperation problems. This perspective resonates with institutional practice, where IO reforms often involve changes to several design features simultaneously, rather than modifications of one at a time. We argue that reaping the resource benefits of TNA access depends on higher levels of pooling, and that lower levels of delegation to supranational bodies will make it easier to

\footnotetext{
${ }^{2}$ Lall (2017) speaks about instiutional design in terms of de jure political autonomy and finds that only de facto autonomy will result in better IO performance. However, his understanding of IO performance differs from our concept of decision-making performance.
} 
realize the positive effects of pooling. Moreover, we expect that delegation's effects on decision-making should be reinforced by extensive TNA access.

Third, we offer the first comparative assessment of the decision-making performance of IOs. While existing research analyzes the decision-making of individual IOs, such as the UN (Holloway \& Tomlinson, 1995; Allen \& Yuen 2014; Vreeland \& Dreher, 2014), EU (Schulz \& König, 2000; Thomson et al. 2006; Naurin \& Wallace 2008), and World Trade Organization (WTO) (Ehlermann \& Ehring, 2005; Elsig, 2010), these studies tell us little about general patterns and explanations of IO decision-making performance. The broad comparative studies that do exist focus on aspects of IO performance other than decision-making (Gutner \& Thompson 2010; Lall, 2017; Gray, 2018). Our data cover 30 IOs from 1980 to 2011, and captures tens of thousands of decisions of the main decision-making body of these IOs.

Our analysis produces several important findings. Decision-making performance varies both across and within IOs, and institutional design helps to account for this variation. Increased pooling has a positive independent effect on IO decision-making performance in the long run, making it less cumbersome to arrive at collective decisions. Increased delegation and TNA access do not have similar independent effects. Yet more important than the effect of any one institutional design feature is how pooling, delegation, and TNA access interact to shape decision-making performance. We find support for two particular constellations of institutional design: TNA access has a positive effect on decision-making performance when pooling is greater, and the effect of delegation varies with the extent of TNA access. All-inall, these findings suggest that when design features are viewed in isolation of one another, we miss crucial explanations of performance.

This article proceeds in four parts. First, we theorize how institutional design affects IO decision-making, emphasizing the role of pooling, delegation, and TNA access. Second, we present the research design, describing our dataset and introducing our measures of decision-making performance. Third, we present the results of our multivariate analysis of the effects of institutional design on IO decision-making performance. We end with a brief conclusion.

\section{Institutional design and 10 decision-making}

The institutional setting within which IO decision-making occurs has profoundly changed in recent decades, potentially affecting if and how decisions are made. Three changes have moved IOs from pure intergovernmental forms of cooperation toward more complex institutional designs. First, the national veto has in many instances been replaced by a pooling of authority through majority voting (Blake \& Payton, 2015; Hooghe et al., 2017). Second, IOs nowadays often involve some delegation of independent authority to international bureaucrats (Hawkins et al., 2006; Hooghe et al., 2017). Third, IOs increasingly provide some access to policymaking for TNAs such as non-governmental organizations (NGOs), business actors, scientific experts, and philanthropic foundations (Steffek et al., 2008; Tallberg et al., 2014). These expansions in pooling, delegation, and TNA access are significant developments in the institutional design of IOs. Each contributes to a reduction in 
member state control. Together, they define the new strategic landscapes in which IOs make decisions. ${ }^{3}$

Figure 1 illustrates these changes by positioning 30 IOs in a three-dimensional space at three points in time. The figure shows how many of these IOs already in 1980 used designs that did not conform to the intergovernmental end of the spectrum (lower left-hand corner, represented by ASEAN), and how these IOs then successively expanded pooling, delegation, and TNA access up to 2010, approaching the opposite end (upper right-hand corner, represented by the EU). In addition, the figure illustrates how these developments have contributed to greater diversity in the design of IOs over time, as these organizations to varying extents have expanded pooling, delegation, and TNA access.

Our account focuses on these developments to generate expectations about the effects of institutional design on decision-making within IOs. It moves beyond a conventional treatment of IOs as arenas for pure intergovernmental bargaining to theorize how these three design features-on their own and in combination-affect IOs' capacity to come to agreement in the face of pressures to address societal problems. Our account is rooted analytically in rational choice institutionalism, which assumes that decision outcomes are the result of strategic interactions between goal-oriented actors operating within institutional constraints (Scharpf, 1997; Lake \& Powell, 1999; Shepsle, 2008; Martin \& Simmons, 2012). Moreover, we assume that institutional designers adopt certain institutional features in order to mitigate cooperation problems (Koremenos et al., 2001). Whether IOs perform well, in our account, is therefore a result of how design features are combined in ways that mitigate barriers to collective decision-making, such as high transaction costs, information asymmetries, or resource deficits. In the remainder of this section, we discuss how pooling, delegation, and TNA access affect barriers to cooperation to alter the strategic setting in which decisions are made, and derive testable hypotheses about their independent and interdependent effects on IO decision-making performance.

\subsection{Pooling}

Pooling occurs when "authority to make decisions is removed from individual states" (Keohane \& Hoffman 1991, p. 7) and it requires a coalition of states to block decisions. We can observe pooling through majority and weighted voting rules. Pooling is greatest when decisions are based on a simple majority, requiring a larger coalition of states to block a decision. Pooling is slightly lower when a qualified majority is required, as the blocking coalition necessary to stop a decision is smaller. Finally, when unanimity or consensus is required, pooling is at its lowest, as each state retains the formal ability to veto a decision.

Comparative analysis reveals that pooling varies across IOs and has increased over time (Hooghe et al., 2019, p. 39), as reflected in Fig. 1. Cross-sectional data

\footnotetext{
3 These three features of institutional design overlap with core components of the rational design of international institutions framework (Koremenos et al., 2001). In our empirical analysis, we control for the effects of two components that are not captured by our privileged features (membership and scope).
} 
Fig. 1 Constellations of IO design: pooling, delegation, and TNA access

suggest that pooling is a feature of the majority of IOs. Blake and Payton (2015) show that among 266 IOs in 2004, 44 percent featured majority voting and 18 percent weighted voting. By comparison, 35 percent of IOs featured no pooling, making decisions by unanimity or consensus.

We would expect increased pooling to lower transaction costs and thus have a positive effect on decision-making. The absence of pooling can invite gridlock because any state can block a decision process by wielding the veto. As Blake and Payton (2015, p. 383) explain: "The need to find a universally acceptable outcome means that unanimity is often associated with gridlock, hindering the ability of IGOs to respond quickly and effectively to the shifting demands of their members." In comparison, pooling, which lowers the institutional hurdles to agreement, is more permissive to decision-making. In the language of formal modelling, majority voting enlarges the win-set, increases the proportion of winning coalitions, and expedites decisions (Golub, 2008, p. 169). Scharpf (1997, p. 151) arrives at the same conclusion based on a consideration of transaction costs: "[T]he choices of very large numbers of actors may be coordinated at very moderate transaction costs if collectively binding decisions can be imposed by majority rule." Therefore, we expect:

Hypothesis 1: Increased pooling will have a positive effect on decision-making performance.

\subsection{Delegation}

Delegation is present when states grant authority to a supranational body to take actions and contribute to decision-making on their behalf. Supranational bodies can be tasked with a variety of functions, such as setting an agenda for decision-making, implementing policy through day-to-day managerial decisions, or monitoring compliance through rule interpretation and dispute settlement. In order to carry out these tasks, these bodies have some autonomy or independence from states in the areas of agenda-setting, policy implementation and dispute settlement.

Like with pooling, delegation varies across IOs and has increased over time, as shown in Fig. 1 (see also Hooghe et al., 2019). For example, the EU and the Economic Community of West African States (ECOWAS) have high delegation, while the International Whaling Commission (IWC) and the Organization of Islamic Cooperation (OIC) have low delegation as the autonomy and tasks assigned to an international body are limited.

We would expect increased delegation to reduce barriers to cooperation and thus improve the decision-making performance of an IO. Rational institutionalist scholarship suggests that delegation provides several benefits to international cooperation by way of addressing collective-action problems. Supranational bodies can reduce transaction costs that hinder collective decision-making, reduce information asymmetries, improve the credibility of commitments by monitoring and enforcement, resolve problems arising from incomplete contracts, or enable blame shifting for unpopular or failed policy (Pollack, 1997; Tallberg, 2002; Hawkins et al., 2006; 


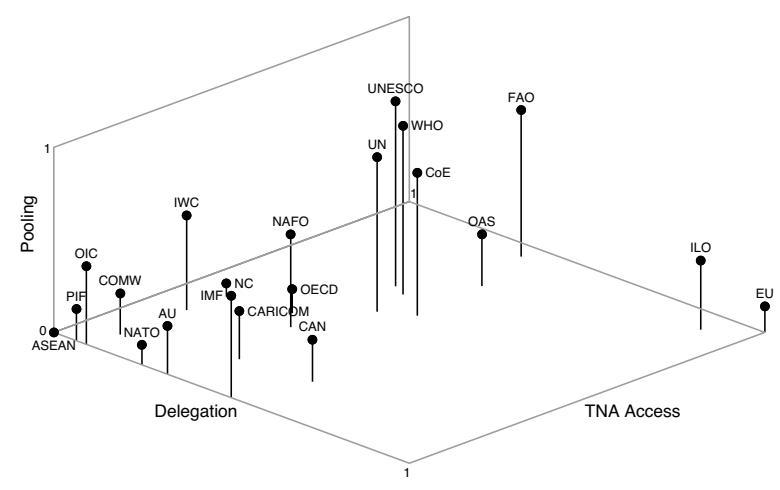

1995

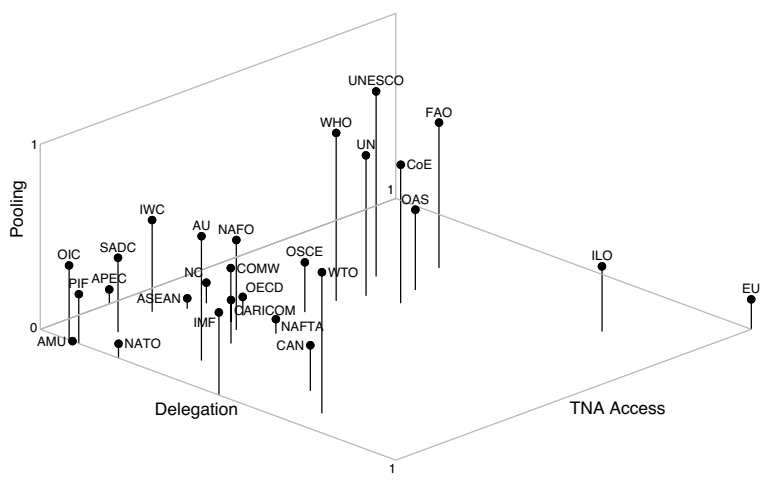

2010

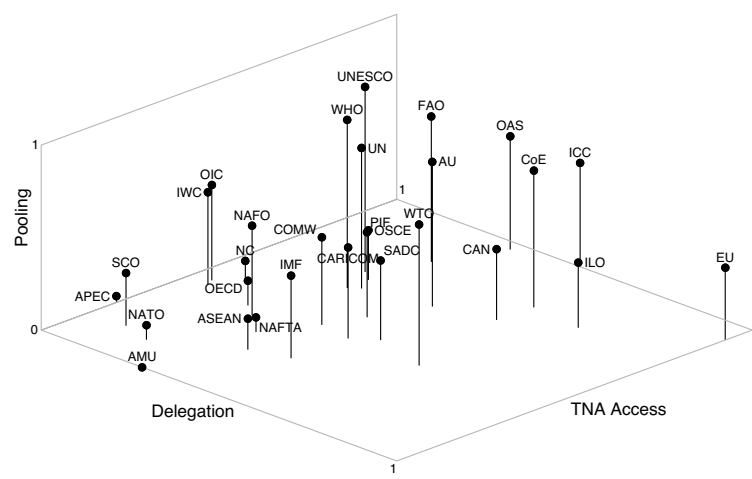


Bradley \& Kelley, 2008). By addressing collective-action problems that might otherwise impede decision-making, supranational bodies improve IOs' ability to conclude decisions. We therefore expect:

Hypothesis 2: Increased delegation will have a positive effect on decisionmaking performance.

This expectation is based on the widely-held rationalist view that delegation improves decision-making. Nonetheless, two additional factors bear mention. First, the impact of delegation on decision-making may vary depending on whether supranational bodies have independence in agenda-setting, implementation, or dispute settlement. In some areas, it is conceivable that delegation could reduce intergovernmental decision-making as well. For example, delegation of implementation to a supranational bureaucracy could supplant intergovernmental decision-making, and delegation of dispute settlement could lead an intergovernmental body to defer difficult decisions to a supranational interpretive body. Second, some scholarship suggests that delegation can have perverse effects. Empowering an autonomous supranational body can lead it to pursue its own agenda (Pollack, 1997; Barnett \& Finnemore, 2004). Preventing and countering such pathologies is politically costly and resource intensive (Hawkins et al., 2006). Delegation in this view might encumber decision-making because state monitoring of supranational organs increases transaction costs and demands resources.

\subsection{TNA access}

TNA access is defined by formal privileges for transnational actors to participate in decision-making and other governance functions. It enables TNA involvement through opportunities to observe, address, or even vote in interstate decision-making (Tallberg et al., 2014). TNA access provides such opportunities to a variety of actors, from scientific experts and professional organizations to business associations, NGOs, and advocacy groups.

TNA access has expanded greatly in recent decades, yet continues to vary across IOs, as shown in Fig. 1 (see also Steffek et al., 2008; Tallberg et al., 2014). While some IOs have become open to the involvement of TNAs, others remain more closed.

We would expect increased TNA access to have a positive effect on decisionmaking. Previous research suggests that an IO's cooperation with TNAs can improve its performance (Lall, 2017). TNAs can provide resources that affect whether collective solutions are reached. When IOs address complex problems, finding collective solutions may require expert or local information and resources. IOs often lack such information and resources, and distributional problems can prevent states from individually providing them. TNAs can fill these gaps and thus enable decision-making (Raustiala, 1997; Betsill \& Corell, 2008; Abbott et al., 2015). In addition, TNA access can improve decision-making performance by reducing IO legitimacy deficits. As the legitimacy standards for IOs have shifted toward norms of inclusiveness (Dingwerth et al., 2019), organizations that exclude TNAs from participation often 
face internal or external criticism and contestation, making it more difficult or costly for member states to enact decisions (O'Brien et al., 2000). Overall, TNA access provides several benefits to decision-making. Consequently, we expect:

Hypothesis 3: Increased TNA access will have a positive effect on decisionmaking performance.

While most understandings of the role of TNA access would lead us to expect a positive effect, it is possible that TNA access could constrain efficient decision-making as well. Transaction costs may be greater because access implies more actors are involved in decision-making and typically will present additional preferences and positions. For example, Rasmussen and Toshkov (2013) find that TNA consultation processes slow down EU decision-making because of the heightened transaction costs.

\subsection{Combinations of pooling, delegation, and TNA access}

Pooling, delegation, and TNA access are distinct dimensions of institutional design, each with its own potential independent effects on the decision-making performance of IOs. Yet IOs combine these three design features in a variety of constellations (as illustrated in Fig. 1). This raises the question of how pooling, delegation, and TNA access interact to affect decision-making. Are some combinations of these three features particularly beneficial or unhelpful for decision-making in IOs? Surprisingly, the interplay between these three design features has received very limited attention in previous scholarship. This is puzzling, since these three dimensions can be expected to affect each other in theory and often are reformed together in practice. For instance, when the decision-making arrangements of the EU were revised in the 1990s and 2000s, the reforms involved carefully calibrated changes to all three features: pooling, through an expansion of qualified majority voting; delegation, through more delegation of authority to the European Commission and the European Parliament, and TNA access, through greater involvement of interest groups and civil society. In the following, we offer a first attempt to theorize the interplay between pooling, delegation, and TNA access. Building on our general theoretical framework, we develop expectations about three interaction effects that we find particularly plausible. Each expectation focuses specifically one of our key design features and how it interacts with another design feature to affect IO decision-making performance. $^{4}$

First, TNA access coincides with different levels of pooling. For example, TNA access and pooling are both relatively high in United Nations Educational, Scientific and Cultural Organisation (UNESCO), while the International Labour Organization

\footnotetext{
4 We do not theorize on 3-way interaction effects. In the following, we theorize the two-way interactions in ways that are most theoretically grounded. But as with all interactions, they can go the other way. Alternative interpretations will be discussed for significant interaction terms in the results section.
} 
(ILO) features high TNA access combined with low levels of pooling. We expect that pooling will have a positive influence on the effects of TNA access on IO decision-making. TNA access can provide resources that enable IO decision-making, but these benefits are more easily realized when pooling is extensive. A higher level of pooling raises the threshold for states to block TNAs' contributions. In contrast, an absence of pooling means that any single state can block a decision, and thereby undermine the contributions made by TNAs. Returning to our examples, UNESCO's higher degree of pooling may thus increase the benefits of TNA access for decisionmaking compared to the ILO's lower level of pooling, all else equal. Overall, reaping the resource benefits of TNA access may depend on having less onerous voting rules. Thus, we would expect:

Hypothesis 4: Increased TNA access will have a stronger positive effect on decision-making performance at higher levels of pooling.

Second, pooling is combined with different degrees of delegation. For example, the Food and Agriculture Organization (FAO) and the International Criminal Court (ICC) have similar levels of pooling, but the latter has considerably higher levels of delegation. We expect that delegation will negatively influence the effects of pooling on IO decision-making. When delegation is higher, it will be more difficult to realize the benefits of pooling. Supranational bodies often develop preferences that diverge from those of states (Hawkins et al., 2006). When delegation expands the authority of supranational actors, it therefore increases the preference heterogeneity among decision-makers, reducing the benefits of pooling for the IO's ability to come to agreement. For example, König (2007; see also Golub, 2008) finds that greater delegation of decision-making authority to the European Parliament reduced the decision-making benefits of the simultaneous shift toward qualified majority voting, or more pooling, in the Council of the EU. Conversely, the benefits of pooling are more likely to be realized when delegation is lower and decision-making largely or exclusively is a question of interstate bargaining. In this case, it matters greatly for an IO's ability to come to agreement whether decisions require the support of a simple majority, a qualified majority or the entire membership. Thus, we expect:

Hypothesis 5: Increased pooling will have a stronger positive effect on decisionmaking performance at lower levels of delegation.

Finally, delegation combines with varying degrees of TNA access. Some IOs, such as the EU, feature high delegation alongside high TNA access. Other IOs, such as the North Atlantic Treaty Organization (NATO), combine high delegation with low access for TNAs. We expect that delegation will have a more positive effect on IO decision-making at higher levels of TNA access. Cooperation with TNAs can help supranational bodies to pursue their interests and maintain their autonomy (Lake \& McCubbins, 2006), overall reducing transaction costs and resource deficits. To begin with, TNA access can assist supranational bodies in building a network of nonstate partners to support their proposals in the policy-process. For instance, when the European Commission develops new proposals for EU rules, it relies extensively on input from business, civil society, and scientists, provided through a system of 
expert committees (Gornitzka \& Sverdrup, 2011). In addition, TNA access can help supranational bodies to enlist societal actors as watchdogs in the monitoring of state compliance, thus strengthening the credibility of commitments (Tallberg, 2015). For example, supranational bodies engaged in the monitoring of human rights are particularly reliant on information from NGOs (Landolt \& Woo, 2017). Research also suggests that international courts benefit extensively in their work from cooperation with compliance constituencies (Alter, 2014). These examples suggest that delegation's effects on decision-making should be reinforced by extensive TNA access. Thus, we expect:

Hypothesis 6: Increased delegation will have a stronger positive effect on decisionmaking performance at higher levels of TNA access.

\section{Decision-making performance: a new dataset}

In the previous section, we developed theoretical expectations about the independent and combined effects of pooling, delegation, and TNA access. In this section, we introduce our data on IO decision output and then describe how we deal with the challenge of comparing decision-making across a heterogenous sample of IOs. We construct a novel measure based on growth rates within IOs, add a comprehensive set of control variables, and use a regression model with IO-fixed effects.

To study the decision-making performance of IOs, we use a new dataset covering the yearly policy output of the principal interstate decision-making bodies of 30 IOs from 1980 to $2011 .^{5}$ Our 30 IOs were selected via a stratified random sample from a list of IOs drawn from the Correlates of War IGO (COW-IGO) Dataset (Pevehouse et al., 2020), adjusted based on data availability in parallel datasets (Tallberg et al., 2014; Hooghe et al., 2017) (Table A.1 in the online appendix). ${ }^{6}$ The sample is composed of 15 global and 15 regional IOs and it contains 15 task-specific IOs and 15 IOs dealing with a wide range of policy issues (see Table A.2 in the online appendix). ${ }^{7}$

We focus on the policy output of the main interstate decision-making bodies, such as the Council of the EU or the General Assembly of the Organization of American States (OAS). These bodies are the principal locus of authority in an IO, establish its core policy direction, and set the overall agenda for other IO bodies. They are the closest approximation to the domestic notion of a legislator and can make political commitments that represent the collective will of the IO. In comparison, policies developed in other parts of an IO's machinery are not suitable indicators for an IO's overall decision-making performance. IO bureaucracies or lower-level IO bodies

\footnotetext{
5 The data on decision-making is available for a longer time period, but data for the main independent variables is limited to 2011 when we use a time lag of one year.

6 The online appendix is available on the Review of International Organizations' webpage.

7 Global IOs have members from more than two world regions. Multi-issue IOs operate in several policy fields and lack a single dominant issue area.
} 
may produce policy reports, but such documents do not necessarily reflect the collective will or commitment of the IO membership. Focusing on the main decisionmaking body makes IOs more comparable. It also eliminates the risk of doublecounting decisions, which could occur if the main body and preparatory bodies publish drafts of the same policy. We assume that activities at lower levels of the IOs are channeled into decisions by the main decision-making body. We select the main decision-making body according to the specification of organizational tasks in IO founding treaties (Table A.1 in the online appendix). In cases where more than one body exists at the same level-typically multiple ministerial councils for different issue areas-we code all bodies as one. ${ }^{8}$

We collected information on the number, type, and bindingness of all decisions of the selected bodies. ${ }^{9}$ In many cases, main decision-making bodies adopt different types of decisions, such as resolutions, declarations, decisions, statements, and directives. We capture all types, following the nomenclature stipulated by each IO. Some of the decision-making bodies do not publicize individual decisions, but provide a summary of decisions (e.g., communiques) taken in a meeting of the main decision-making body. In order to make this output comparable to that of other decision-making bodies, we disaggregated these summaries into individual decisions. ${ }^{10}$

Before we introduce our measure of decision-making performance, we present data on the raw count of IO decisions for a selection of four IOs (Fig. 2). ${ }^{11}$ These data reveal two dominant patterns, general to our sample, which have implications for the measurement of IO performance.

First, there is no consistent trend (positive or negative) in IO decision-making. We see neither an ever-growing amount of decisions, nor a severe waning that might point to a systemic crisis for global governance. Instead, as selectively illustrated in Fig. 2, our data contain a range of different temporal patterns. Some IOs, like the African Union (AU), show a positive trend, whereas other IOs, including the World Health Organization (WHO), display declining output over time. What most IOs have in common, though, are periods of growth as well as decline in decisionmaking volumes.

Second, the absolute level of decision-making in these IO bodies varies dramatically. Figure 2 shows that the output ranges from several hundred decisions a year, as in the case of the EU, to only a dozen decisions a year, as in the case of the IWC.

\footnotetext{
8 In the case of the UN, we select the Security Council over the General Assembly.

9 Where data were not electronically available, we contacted IO secretariats and repository libraries or used secondary sources to complete the information.

10 Excluding decision summaries from the sample would lead to a biased representation of decisionmaking in global governance. We control for type of decision (i.e., output) in the explanatory analysis.

11 For an illustration of the trend for all 30 IOs, see Figure A.2 in the online appendix).
} 


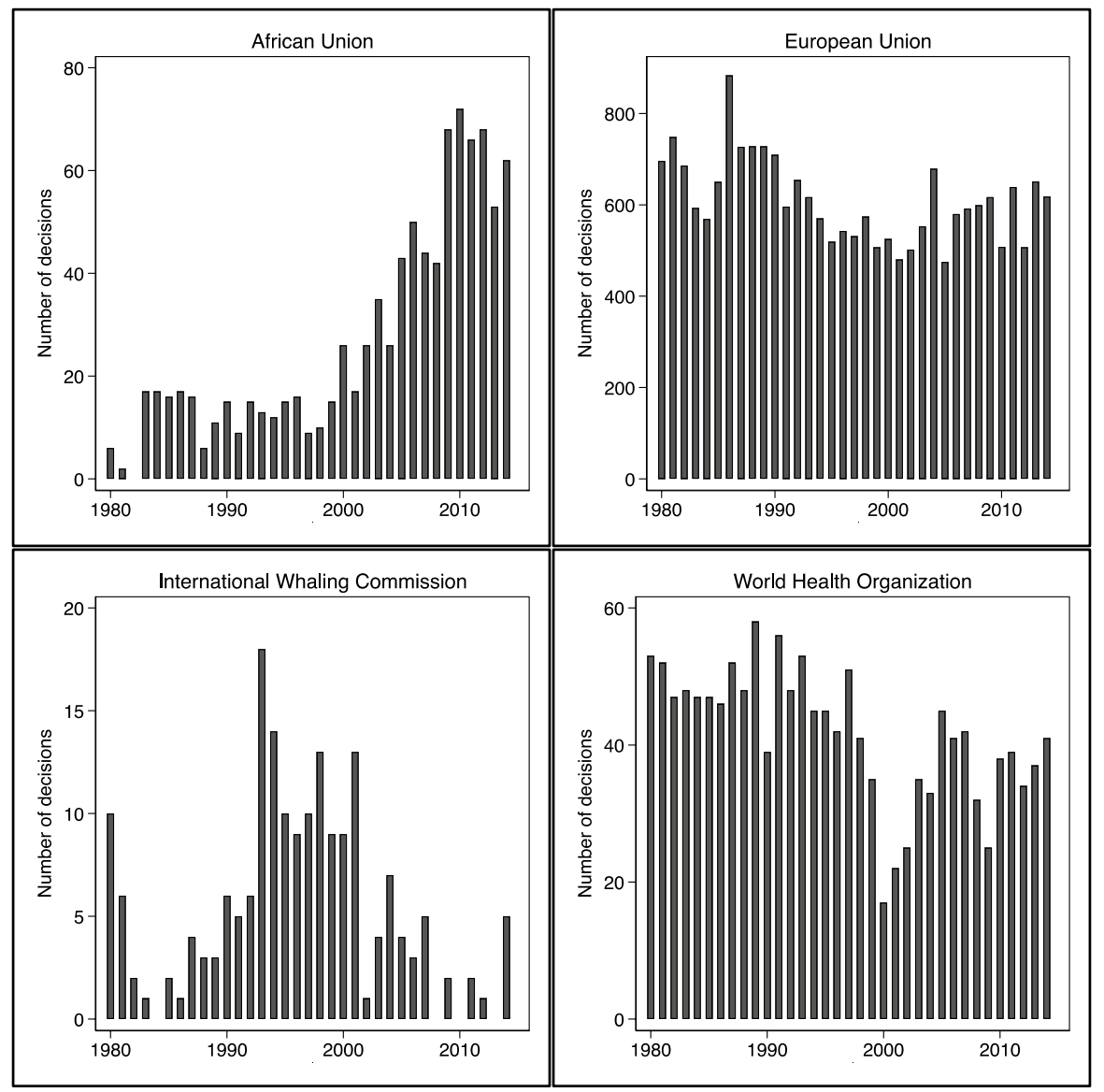

Fig. 2 Number of decisions, four IOs

\subsection{Measuring 10 decision-making performance}

Studies of decision-making performance in the context of individual IOs commonly use measures based on count data. ${ }^{12}$ However, count data are inappropriate as a measure when analyzing a larger number of IOs, since the general levels of output vary substantially across organizations, as illustrated by Fig. 2. In an analysis using simple count data, variation across units would therefore overshadow the much smaller but important variations over time. Such analyses would thus mainly capture structural differences across IOs that are of limited theoretical interest, such as differences in the scope of the mandate of the EU and the IWC.

\footnotetext{
12 Alesina et al. (2005) have mapped the expansion of EU legislation by the number of legal acts (see also Golub1999; Christensen 2010). Similarly, scholars have assessed the policy volume of the UN General Assembly (Marín-Bosch 1987; Holloway and Tomlinson 1995) and the UN Security Council (Allen and Yuen 2014). In studies of international courts, the volume of decisions often features as an indicator of their effectiveness, like in the case of the European Court of Human Rights (Alter 2014; Cichowski 2006).
} 
To systematically compare IO decision-making performance, we instead introduce a measure based on growth rates of decision output. Inspired by Mitchell (2002), we suggest that growth rates help to deal with the problem of heterogeneity among IOs, next to other measures. ${ }^{13}$ First, using growth rates as a measure to normalize data "makes otherwise disparate data relatively comparable by adjusting for the initial level of the underlying activities. Calculating those percentage changes on an annual basis provides the additional benefit of re-calibrating (and thus allowing comparison across) every year" (Mitchell, 2002: 71). Thus, cross-sectionally, we are not comparing output to output but growth curves to growth curves. ${ }^{14} \mathrm{Sec}-$ ond, growth rates allow for comparison across IOs while also capturing over time variation within IOs. This serves our theoretical interests by enabling us to assess whether changes in the institutional design of a specific IO translate into changes in the growth rate of policy output. This measure of decision-making performance assumes that positive growth rates are indicative of more smoothly functioning IO machineries, while negative growth rates are indicative of IOs confronting discord and deadlock. One could object that IOs which adopt fewer decisions over time might be becoming more efficient, by conveying the same policy content in fewer decision acts, or that IOs which generate more decisions over time in fact may be becoming less efficient, by privileging an appearance of productivity. We recognize that such cases might exist. But we consider our assumption more reasonable as a starting point and note several anecdotal examples pointing in its favor. For instance, the growing productivity of the UN Security Council in the 1990s reflected smoother decision-making as the great powers vetoed fewer proposals in the new post-Cold War climate. Conversely, the drop in productivity for the WTO over the past two decades reflects the high level of discord in the organization, also illustrated through the lack of progress on the Doha Round.

Building on this strategy of growth rates, we introduce two different measures based on two alternative benchmarks. First, we measure short-term performance, comparing the output in the year of observation with the output in the three preceding years. This approach captures short-term changes while leveling out extreme events. If the output remains at the same level, the score of this measure is 1 , and a score above 1 suggests an increase in decision-making productivity. ${ }^{15}$ Since the short-term volatility in policy output is high, we use the log of decisions in a given year. ${ }^{16}$ Second, we measure long-term performance, comparing the output in the year of observation against the mean output across all prior years. ${ }^{17} \mathrm{By}$

\footnotetext{
13 In our modelling approach, we adjust for IO heterogeneity by including IO fixed effects and control variables for bindingness, style, and number of decisions.

14 This means that more output is equivalent to higher decision-making performance, but only for overtime comparisons within an IO. We do not argue that a higher volume of output in $\mathrm{IO}_{\mathrm{x}}$ indicates that its decision-making performance is greater than that of $\mathrm{IO}_{\mathrm{y}}$.

15 In the few cases when an IO body did not meet in the preceding year, we extend the reference period by one year.

16 For the beginning of the observation period, we allow for a shorter reference period of two years to minimize the loss of information.

17 Similar to the first measure, we allow for a shorter reference period in the beginning of the observation period. Again, we use the logged version of the absolute count to calculate the change rate.
} 


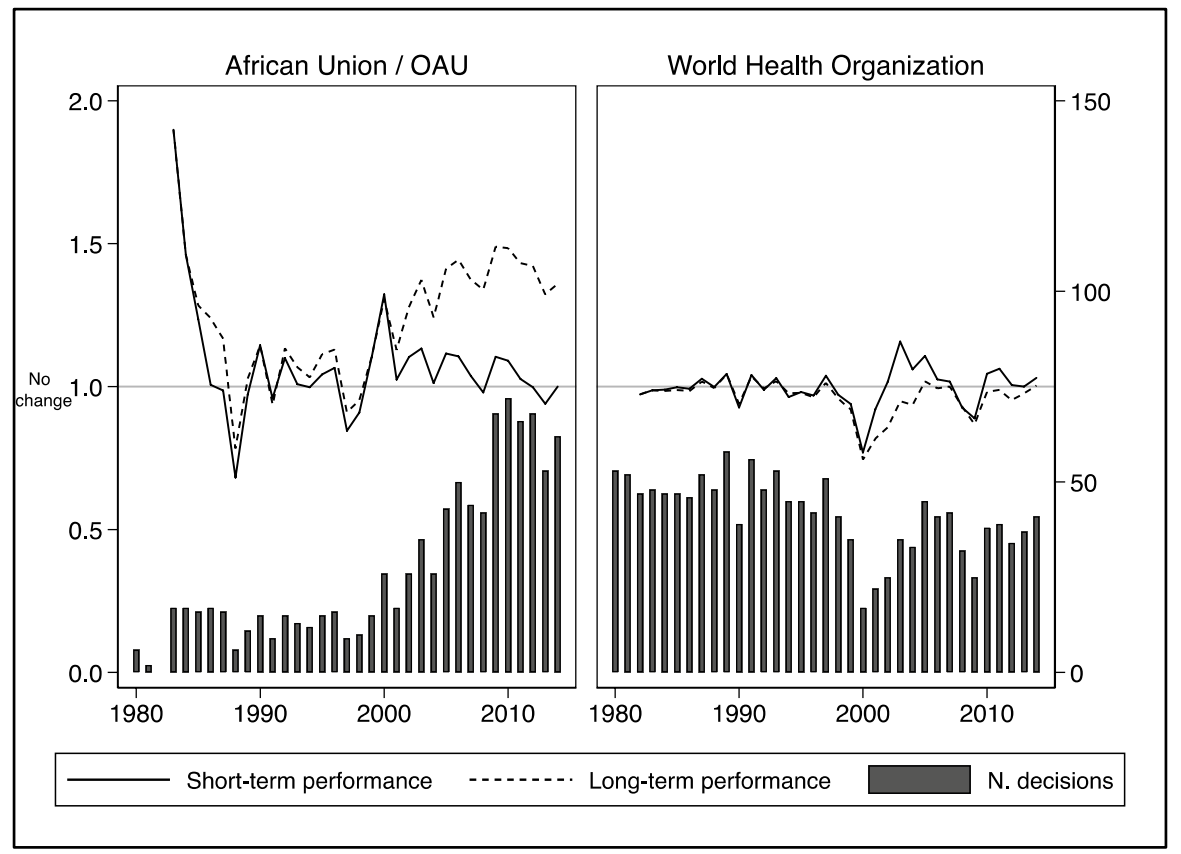

Fig. 3 Measures of IO decision-making performance, two illustrations

encompassing the entirety of an IO's past history, this measure privileges the detection of structural shifts in decision-making.

Our measures are complementary and shed light on two slightly different aspects of the decision-making performance of IOs. In some cases, only one of the measures can adequately capture a change in the decision-making performance of an IO. For instance, when an IO recovers from a crisis only the short-term performance measure may capture this upward trend. Conversely, when the decision output of an IO reaches and remains at an average level that exceeds that of previous decades, even limited dips can lead to positive scores for long-term performance.

Figure 3 illustrates the two measures based on data for the AU and WHO. ${ }^{18}$ In the case of the AU, both measures indicate growing decision-making performance in the mid-1980s, followed by a stable level of performance until the mid-1990s, and then a slight dip. The transformation of the Organization of African Unity (OAU) into the AU in 2002 led to several years of growing decision output, initially reflected as positive scores for both performance measures. However, after a few years of growth, the scores diverge as the result of a plateau effect for short-term performance: once a higher level of output is obtained for a number of years in a row, this measure does not indicate high performance any longer, as intended in our construction of the measure. At the same time, the measure of long-term performance continues to increase, as a result of the longer historical baseline.

\footnotetext{
${ }^{18}$ See Figure A.1, A.2, and A.3 in the online appendix for an overview of the index scores for the full sample.
} 
The WHO represents a different pattern. During the first half of the observation period, the number of decisions was relatively stable, and the difference between short-term and long-term decision-making performance is therefore negligible. From 2000 onwards, the World Health Assembly underperformed for a number of years vis-à-vis both its historical and recent average, which is reflected in both measures. But whereas the measure for short-term performance then recovers quite quickly, as the number of decisions doubled between 2000 and 2003, the measure for long-term performance takes longer to catch up, reflecting the differences in construction of the two measures.

\section{Explanatory analysis}

We assess the influence of institutional design on IO decision-making performance on the basis of recent data on institutional features of IOs, reflecting our interest in the threefold shift away from the classic intergovernmental model of IO design: pooling, delegation, and TNA access. We measure the effect of majoritarian decision rules (H1) through aggregated pooling scores taken from the Measuring International Authority dataset (MIA; see Fig. 1). ${ }^{19}$ It aggregates the voting rules for agenda-setting and final decisions across the "state-dominated bodies" of an IO, weighted by bindingness and ratification. ${ }^{20}$ For all our main explanatory variables, we use two different versions. A first one captures the absolute level of pooling (and delegation and access) in any given year. While the time series structure of our data accounts for year-on-year changes, we add a version that indicates recent changes to design features, meaning that our $\Delta$-variables, such as $\Delta$ Pooling, only capture the effect of changes between $t-2$ and $t-1$ on decision-making in $t 0$. When we interact both versions, this combination allows us to better understand how institutional design affects decision-making; for example, do we only see a positive effect of pooling in IOs previously dominated by consensus, or does additional pooling lead to positive growth rates even for IOs that already resorted to majority decision-making?

We measure delegation as the allocation of authoritative competences to nonstate bodies in an IO's decision-making process (MIA). The measure aggregates political delegation in agenda setting, decision-making, and dispute settlement across six decision areas: accession, suspension, constitutional reform, budgetary allocation, financial compliance, and policy making (Fig. 1; Hooghe et al., 2017).

We measure TNA access based on the depth and range of formal access to an IO's bodies (Fig. 1; Tallberg et al., 2014). These two dimensions are constitutive of all participatory arrangements by defining what rights are granted and to whom. The depth of access captures the level of involvement offered to TNAs through institutional rules, and the range of access captures the breadth of TNAs entitled to participate.

\footnotetext{
19 Hooghe et al., 2017.

${ }^{20}$ For a full description of the coding of this variable, see Hooghe et al., 2017, 213-217.
} 
We add a number of control variables to account for systematic differences across IOs. Membership and policy scope are two additional features of institutional design (Koremenos et al., 2001). With regard to membership, IR scholars have theorized that international cooperation is more difficult to establish and sustain with greater numbers of players (Axelrod \& Keohane, 1985). Controlling for membership also helps to account for changes in output that might be driven by fluctuations in any given IO's membership. We operationalize membership as the number of member states in a given year, using data from the COW-IGO dataset (Pevehouse et al., 2020). In terms of the scope of the issues covered by an IO, we expect it to be positively correlated with IO decision-making performance, since issue-linkages facilitate agreement and cooperation in international politics (Axelrod \& Keohane, 1985: 239). By including a measure for policy scope, we are able to control for any changes to an IO's mandate over time. We capture the policy scope based on the MIA data, which measure scope as the number policy areas, ranging from one to 25 , within an IO's mandate (Hooghe et al., 2019).

Decision-making performance may also depend on the resources and capabilities of IOs (Elsig, 2010; Lall, 2017; Gray, 2018). IOs with greater administrative capabilities can maintain a higher decision-making performance. We operationalize organizational capacity of IOs as the annual count of IO staff, using data sourced from IO annual reports, UN Yearbooks, and historical editions of the Yearbook of International Organizations (see Table A.3 in the online appendix).

Recent scholarship finds that competition from other IOs active in the same area affects IO performance. Gray $(2018$, p. 5) shows that IOs seeking to promote economic cooperation have a hard time remaining active if they operate alongside other IOs with similar agendas. We capture IO competition with the number of IOs that operate in the same world region, based on the COW-IGO dataset (Pevehouse et al., 2020).

We control for the influence of powerful member states. Realist accounts of international cooperation typically reduce IO decision-making to strategic interaction among dominant states (Drezner, 2007; Stone, 2011). According to this logic, hegemons that dominate an IO have a positive influence on collective decisionmaking, whereas competing major powers can lead to deadlock of an institution, as witnessed in the UN Security Council during the Cold War. We construct a dummy for IOs with an unchallenged major power. We follow the COW operationalization of major powers and add regional powers for the period after 1989 (see Cline et al., 2011).

Previous research suggests that democracies participate more in cooperative solutions, whether it be international human rights promotion (e.g., Simmons, 2009), trade liberalization (e.g., Mansfield et al., 2002), or international cooperation more broadly (e.g., Mansfield \& Pevehouse, 2008). We operationalize the domestic commitment to democratic ideas as the democratic density of IOs, operationalized as the share of member states with democratic regimes. We combine information on state membership in IOs from the COW-IGO dataset with information on the democratic character of domestic regimes (Cheibub et al., 2010; Tallberg et al., 2016b).

We also control for preference heterogeneity. Previous research argues that greater heterogeneity of preferences can impede decision-making (Axelrod \& 
Keohane, 1985). We use a measure of voting patterns in the UN General Assembly (UNGA) as predictor of preference heterogeneity. The more similar member states of an IO vote in the UNGA, the more homogenous their preferences are assumed to be. We use the updated data on the dyadic affinity scores from Voeten (2013).

We control for the politicization of an IO (Zürn et al., 2012), as decision output could be positively or negatively affected by an IO being in the public spotlight. We use an indicator that captures IO media coverage as references to the name in six leading global newswires (Bes et al., 2019), assuming that more references are equivalent to higher public attention.

We include the lagged number of decisions to control for differences in the level of productivity, and we expect that the absolute number of decisions is negatively correlated with the change rate of an IO decision-making body. The variable bindingness captures the share of binding decisions in the annual output of an IO. ${ }^{21}$ And finally, we include a dummy variable for communiqué-style IOs that do not issue individual decisions, expecting that lower formality in decision-making output leads to higher volatility. Both of these variables control for the type of policy output.

To test our hypotheses regarding IO decision-making performance, we employ linear regression models. In addition to the control variables that cover a range of alternative explanations, we add IO dummies to account for IO-specific effects and year-fixed effects to capture events that affect all IOs in a similar way. ${ }^{22}$ All independent variables are lagged by 1 year. We cluster standard errors at the IO level to account for potential dependence within units. To test our hypotheses on the independent effects of institutional design, we first estimate a series of regression models of short-term performance and long-term performance (Table 1). We vary the specifications to test the effects of the absolute levels of delegation, pooling, and TNA access (Models 1 and 4); the effect of changes in delegation, pooling, and TNA access (Models 2 and 5); and the effect of interactions between absolute levels and changes (Models 3 and 6). We then test our hypotheses on the interaction between the three dimensions of institutional design (Table 2; Model 7-14). Tables 1 and 2 show only those models with significant interaction terms.

\section{Results}

What role do the institutional design features of pooling, delegation, and TNA access have in explaining the decision-making performance of IOs? Our findings suggest that some features of institutional design have an independent effect, but that the most substantive effects emerge when these features interact to produce constellations beneficial for decision-making. These findings are robust to alternatives to our main modelling strategy. In this section, we elaborate on these findings.

\footnotetext{
${ }^{21}$ Bindingness is coded in a binary way for each type of decision instrument. In some cases, bindingness varies within instruments. For the analysis later on, we operate with the rate of binding decisions at the body-level.

22 A Hausmann test supports this theoretical argument.
} 
Table 1 Institutional design and decision-making performance of 30 IOs, 1980-2011

\begin{tabular}{|c|c|c|c|c|c|c|}
\hline \multirow{3}{*}{$\overline{\text { Pooling }}$} & 1 & 2 & 3 & 4 & 5 & 6 \\
\hline & \multicolumn{3}{|c|}{ Short-term performance } & \multicolumn{3}{|c|}{ Long-term performance } \\
\hline & 0.267 & 0.361 & 0.359 & 0.561 & 0.680 & 0.724 \\
\hline & {$[0.286]$} & {$[0.290]$} & {$[0.286]$} & {$[0.239]^{*}$} & {$[0.237]^{* *}$} & {$[0.238]^{* *}$} \\
\hline \multirow[t]{2}{*}{$\Delta$ Pooling } & & -0.099 & -2.351 & & -0.295 & -0.339 \\
\hline & & {$[0.343]$} & {$[1.170]^{*}$} & & {$[0.239]$} & {$[0.256]$} \\
\hline \multirow[t]{2}{*}{ Pooling $* \Delta$ Pooling } & & & 6.462 & & & \\
\hline & & & {$[3.287]^{*}$} & & & \\
\hline \multirow[t]{2}{*}{ Delegation } & -0.746 & -0.633 & -0.642 & -0.582 & -0.499 & -0.575 \\
\hline & {$[0.333]^{*}$} & {$[0.326] \dagger$} & {$[0.323]^{*}$} & {$[0.160]^{* *}$} & {$[0.166]^{* *}$} & {$[0.174]^{* *}$} \\
\hline \multirow[t]{2}{*}{$\Delta$ Delegation } & & -0.060 & -0.023 & & -0.013 & 1.968 \\
\hline & & {$[0.284]$} & {$[0.281]$} & & {$[0.285]$} & {$[0.804]^{*}$} \\
\hline \multirow[t]{2}{*}{ Delegation $* \Delta$ Deleg } & & & & & & -6.444 \\
\hline & & & & & & {$[2.550]^{*}$} \\
\hline \multirow[t]{2}{*}{ TNA access } & -0.031 & -0.009 & -0.004 & 0.026 & 0.038 & 0.037 \\
\hline & {$[0.091]$} & {$[0.096]$} & {$[0.097]$} & [0.097] & {$[0.089]$} & {$[0.088]$} \\
\hline \multirow[t]{2}{*}{$\Delta$ TNA access } & & -0.140 & -0.128 & & -0.024 & 0.033 \\
\hline & & {$[0.184]$} & {$[0.185]$} & & {$[0.129]$} & {$[0.121]$} \\
\hline \multirow[t]{2}{*}{ Membership } & 0.002 & 0.002 & 0.002 & -0.002 & -0.002 & -0.001 \\
\hline & {$[0.002]$} & {$[0.001]$} & {$[0.001]$} & {$[0.003]$} & {$[0.003]$} & {$[0.003]$} \\
\hline \multirow[t]{2}{*}{ Policy scope } & 0.005 & 0.001 & 0.000 & -0.001 & -0.004 & -0.004 \\
\hline & {$[0.007]$} & {$[0.006]$} & {$[0.006]$} & {$[0.006]$} & {$[0.006]$} & {$[0.006]$} \\
\hline \multirow[t]{2}{*}{ IO staff } & 0.005 & 0.032 & 0.032 & 0.026 & 0.050 & 0.052 \\
\hline & {$[0.035]$} & {$[0.024]$} & {$[0.024]$} & {$[0.028]$} & {$[0.022]^{*}$} & {$[0.022]^{*}$} \\
\hline \multirow[t]{2}{*}{ Relevant IOs in system } & 0.003 & 0.004 & 0.003 & 0.012 & 0.012 & 0.013 \\
\hline & {$[0.003]$} & {$[0.003]$} & {$[0.003]$} & {$[0.005]^{*}$} & {$[0.005]^{*}$} & {$[0.005]^{* *}$} \\
\hline \multirow[t]{2}{*}{ Unchallenged major power } & -0.169 & -0.146 & -0.143 & -0.117 & -0.102 & -0.106 \\
\hline & {$[0.130]$} & {$[0.126]$} & {$[0.127]$} & {$[0.081]$} & {$[0.080]$} & {$[0.080]$} \\
\hline \multirow[t]{2}{*}{ Democratic density } & -0.381 & -0.311 & -0.316 & 0.278 & 0.340 & 0.315 \\
\hline & {$[0.298]$} & [0.280] & {$[0.279]$} & [0.269] & {$[0.261]$} & {$[0.246]$} \\
\hline \multirow[t]{2}{*}{ UNGA preferences } & -0.408 & -0.287 & -0.276 & 0.004 & 0.116 & 0.120 \\
\hline & [0.444] & [0.444] & {$[0.440]$} & {$[0.370]$} & {$[0.372]$} & {$[0.373]$} \\
\hline \multirow[t]{2}{*}{ Media coverage } & 0.017 & 0.010 & 0.010 & 0.012 & 0.005 & 0.006 \\
\hline & {$[0.013]$} & {$[0.012]$} & {$[0.012]$} & {$[0.011]$} & {$[0.010]$} & {$[0.010]$} \\
\hline \multirow[t]{2}{*}{ N. of decisions } & -0.058 & -0.051 & -0.050 & 0.059 & 0.065 & 0.064 \\
\hline & {$[0.028]^{*}$} & {$[0.029] \dagger$} & {$[0.029] \dagger$} & {$[0.031] \dagger$} & {$[0.030]^{*}$} & {$[0.030]^{*}$} \\
\hline \multirow[t]{2}{*}{ Bindingness } & 0.319 & 0.323 & 0.326 & 0.203 & 0.199 & 0.203 \\
\hline & {$[0.237]$} & {$[0.235]$} & {$[0.232]$} & {$[0.089]^{*}$} & {$[0.084]^{*}$} & {$[0.082]^{*}$} \\
\hline \multirow[t]{2}{*}{ Communiqué-based } & 0.911 & 1.033 & 1.034 & 1.763 & 1.909 & 1.952 \\
\hline & {$[0.492] \dagger$} & {$[0.393]^{* *}$} & {$[0.396]^{* *}$} & {$[0.557]^{* *}$} & {$[0.507]^{* *}$} & {$[0.498]^{* *}$} \\
\hline \multirow[t]{2}{*}{ Constant } & 0.375 & -0.186 & -0.187 & -2.816 & -3.372 & -3.567 \\
\hline & [1.192] & [1.106] & {$[1.117]$} & {$[1.457] \dagger$} & {$[1.430]^{*}$} & [1.412]* \\
\hline $\mathrm{N}$ & 579 & 576 & 576 & 579 & 576 & 576 \\
\hline $\mathrm{Ll}$ & -12.19 & -4.09 & -3.57 & 141.53 & 156.19 & 158.36 \\
\hline AIC & 74.4 & 56.2 & 55.1 & -233.1 & -264.4 & -268.7 \\
\hline
\end{tabular}

GLM estimator (STATA 16.1), estimations clustered by IO; Robust standard errors in parentheses. IOdummies, year dummies and trend included, but not displayed.

$\dagger \mathrm{p}<0.1 ; * \mathrm{p}<0.05 ; * * \mathrm{p}<0.01$ 
Table 2 Interaction of institutional design and decision-making performance, 1980-2011

\begin{tabular}{|c|c|c|c|c|c|c|}
\hline & 7 & 8 & 9 & 10 & 11 & 12 \\
\hline & Short-term $_{1}$ & erformance & & Long term per & rformance & \\
\hline Pooling & -0.011 & 0.406 & 0.352 & 0.050 & -0.108 & 0.661 \\
\hline & [0.316] & {$[0.511]$} & {$[0.279]$} & {$[0.246]$} & {$[0.507]$} & {$[0.227]^{* *}$} \\
\hline Delegation & -0.722 & -0.581 & -1.027 & -0.537 & -1.372 & -0.913 \\
\hline & {$[0.330]^{*}$} & {$[0.516]$} & {$[0.367]^{* *}$} & {$[0.151]^{* *}$} & {$[0.473] * *$} & {$[0.193]^{* *}$} \\
\hline TNA access & -0.218 & -0.028 & -0.306 & -0.319 & 0.014 & -0.298 \\
\hline & {$[0.147]$} & [0.090] & {$[0.151]^{*}$} & {$[0.145]^{*}$} & [0.089] & {$[0.202]$} \\
\hline Pooling $\times$ access & 0.617 & & & 1.135 & & \\
\hline & {$[0.303]^{*}$} & & & {$[0.409]^{* *}$} & & \\
\hline Pooling $\times$ delegation & & -0.611 & & & 2.932 & \\
\hline & & [1.939] & & & [2.066] & \\
\hline Delegation $\times$ access & & & 0.967 & & & 1.137 \\
\hline & & & {$[0.455]^{*}$} & & & {$[0.651] \dagger$} \\
\hline Membership & 0.001 & 0.002 & 0.001 & -0.003 & -0.003 & -0.003 \\
\hline & [0.002] & {$[0.002]$} & {$[0.002]$} & {$[0.003]$} & {$[0.003]$} & {$[0.003]$} \\
\hline Policy scope & 0.007 & 0.005 & 0.001 & 0.004 & -0.001 & -0.005 \\
\hline & [0.007] & {$[0.007]$} & {$[0.007]$} & {$[0.005]$} & [0.006] & {$[0.007]$} \\
\hline IO staff & 0.008 & 0.002 & 0.017 & 0.031 & 0.042 & 0.039 \\
\hline & [0.034] & {$[0.035]$} & {$[0.036]$} & {$[0.026]$} & [0.033] & [0.031] \\
\hline Relevant IOs in system & 0.004 & 0.003 & 0.004 & 0.014 & 0.013 & 0.013 \\
\hline & [0.003] & {$[0.003]$} & [0.003] & {$[0.005]^{* *}$} & {$[0.005]^{*}$} & {$[0.006]^{*}$} \\
\hline Unchallenged major power & -0.162 & -0.171 & -0.141 & -0.105 & -0.104 & -0.085 \\
\hline & {$[0.131]$} & {$[0.135]$} & {$[0.126]$} & [0.080] & [0.083] & [0.079] \\
\hline Democratic density & -0.385 & -0.388 & -0.339 & 0.270 & 0.309 & 0.327 \\
\hline & {$[0.300]$} & {$[0.311]$} & {$[0.290]$} & [0.269] & [0.274] & {$[0.267]$} \\
\hline UNGA preferences & -0.458 & -0.374 & -0.482 & -0.088 & -0.161 & -0.082 \\
\hline & [0.449] & {$[0.403]$} & {$[0.458]$} & {$[0.367]$} & [0.392] & [0.383] \\
\hline Media coverage & 0.016 & 0.017 & 0.014 & 0.010 & 0.008 & 0.008 \\
\hline & {$[0.013]$} & {$[0.014]$} & {$[0.014]$} & {$[0.011]$} & [0.012] & {$[0.012]$} \\
\hline N. of decisions & -0.059 & -0.057 & -0.056 & 0.057 & 0.058 & 0.060 \\
\hline & {$[0.028]^{*}$} & {$[0.028]^{*}$} & {$[0.028]^{*}$} & {$[0.030] \dagger$} & {$[0.031] \dagger$} & {$[0.031]^{*}$} \\
\hline Bindingness & 0.328 & 0.322 & 0.327 & 0.219 & 0.189 & 0.212 \\
\hline & [0.236] & {$[0.243]$} & {$[0.234]$} & {$[0.089]^{*}$} & {$[0.089]^{*}$} & {$[0.087]^{*}$} \\
\hline Communiqué-based & 0.880 & 0.889 & 1.007 & 1.705 & 1.869 & 1.876 \\
\hline & {$[0.474] \dagger$} & {$[0.494] \dagger$} & {$[0.460]^{*}$} & {$[0.522]^{* *}$} & {$[0.545]^{* *}$} & {$[0.514] * *$} \\
\hline Constant & 0.235 & 0.386 & 0.133 & -3.072 & -2.871 & -3.099 \\
\hline & [1.146] & [1.212] & [1.079] & {$[1.464]^{*}$} & {$[1.427]^{*}$} & {$[1.485]^{*}$} \\
\hline $\mathrm{N}$ & 579 & 579 & 579 & 579 & 579 & 579 \\
\hline $\mathrm{L} 1$ & -11.59 & -12.14 & -10.88 & 144.98 & 143.60 & 144.62 \\
\hline AIC & 73.2 & 74.3 & 71.8 & -240.0 & -237.2 & -239.2 \\
\hline
\end{tabular}

GLM estimator (STATA 16.1), estimations clustered by IO; Robust standard errors in parentheses. IOdummies, year dummies and time trend included, but not displayed.

$\dagger \mathrm{p}<0.1 ; * \mathrm{p}<0.05 ; * * \mathrm{p}<0.01$ 


\subsection{Independent effects of 10 design}

With regard to the independent effects of the three elements of institutional design privileged in our approach, we find that pooling has a positive effect on performance (H1). The coefficient for pooling is positive and significant for long-term performance (Model 4-6, Table 1). Leaving pure intergovernmentalism behind and moving towards majority voting makes IO decision-making more productive in the long run. On average, moving from the first quartile of pooling (0.12) to the third $(0.37)$ is associated with a 0.14 increase in the long-term performance index (see Figure A.4 in the online appendix). By way of example, when the Lisbon Treaty of 2009 increased pooling in the EU from 0.22 to 0.27 , our model predicts a 0.05 point increase in the long-term index. Empirically, we observe a 0.04 increase from 2010 to 2011 , corresponding to an increase of about 120 decisions. The positive interaction term of pooling and $\Delta$ pooling in Model 3 (Table 1) indicates that changes to pooling can improve the short-term performance of IOs. When member states of IOs with an already high level of pooling further expand the use of majority voting - like the AU in 2004-we observe a positive and significant effect on decisionmaking in the short-term. By contrast, if such a reform occurred in an IO dominated by consensus-as in the case of the Arab Maghreb Union (AMU) in 1991, we see a negative net effect for $\Delta$ pooling.

While we expected that delegation of authority to supranational bodies would have a positive effect on decision-making performance (H2), we do not find support for this hypothesis. Instead, decision-making performance appears to be adversely affected by further delegation. This result holds for both short-term and long-term performance (Models 1 and 4, Table 1). The predicted means of our dependent variable in Figure A.5 (in the online appendix) show that moving from the first quartile of delegation (0.08) to the third (0.25) is associated with a decrease of the shortterm index score from 1.14 to 1.02 . As an example, holding all other characteristics of the IWC fixed at their 1991 levels, such a shift in delegation would translate into a decision output of four, instead of the six resolutions it did pass. A minor exception to this pattern of negative effects is the positive effect of increased delegation on long-term performance for IOs with no prior delegation (Model 6, Table 1). It suggests that an extension of delegation from very low levels can have positive effects, as illustrated by the examples of Asia-Pacific Economic Cooperation (APEC) in the mid-1990s and the Shanghai Cooperation Organization (SCO) in 2005, both of which showed growing decision rates once they started to build up administrative capacities.

While the limited support for Hypothesis 2 goes against widely held expectations concerning the benefits of delegation for decision-making, this negative effect might be caused by the costs that delegation carries alongside its recognized benefits (Tallberg, 2002; Bradley \& Kelley, 2008). For example, autonomous supranational bodies can pursue their own preferences (Pollack, 1997; Barnett \& Finnemore, 2004), requiring states to invest scarce resources and time in monitoring supranational bodies (Hawkins et al., 2006). In addition, it may be that delegation in some areas of the policy process replaces intergovernmental decision-making - a possibility we test for below in the robustness checks. 
Neither do we find support for an independent positive effect of TNA access (H3). This result holds for short- and long-term performance. Involving TNAs in policymaking does not appear to have a systematic independent influence on the ability of IOs to increase their decision-making output. These findings suggest that TNA access may have mixed effects on decision-making (Rasmussen \& Toshkov, 2013), and may indicate that the benefits of TNA access relate to the quality and design of individual policies rather than the overall ability of IOs to arrive at decisions.

\subsection{Interactions between pooling, delegation, and access}

The mixed evidence for the expected independent positive effects of pooling, delegation, and access $(\mathrm{H} 1-\mathrm{H} 3)$ may raise doubts as to whether the decline of the archetypical state-dominated IO translates into more efficient and productive global governance. Our analysis, however, shows that positive effects become visible when we look at the interplay between these elements of institutional design (H4-H6). More than two thirds of all organizational reforms captured in our data include more than one design element in a single reform, and more than 50 percent include all three elements. We find a number of significant interaction effects, the majority of which are positive. This suggests that institutional design matters for decision-making performance, but mainly in more complex ways than typically expected.

As predicted, we find that increased TNA access has a stronger positive effect on IO decision-making at higher levels of pooling (H4). When the adoption of decisions is not based on a consensus rule, expanding the inclusion of non-state actors increases decision-making performance. This result holds for both short-term performance (Model 7, Table 2) and long-term performance (Model 10, Table 2). We show the predicted means of our dependent variable for this interaction in Fig. 4. We now observe that the prediction for moving from the first quartile of TNA access $(0.17)$ to the third $(0.74)$ varies with the level of pooling. While this shift at the lowest level of pooling is associated with 0.17 decrease in the long-term performance index, it contributes to a 0.24 increase at the highest level of pooling. The Andean Community (CAN) exemplifies how the impact of increased TNA access is conditioned by the degree of pooling. When the organization started to expand access arrangements for TNAs in 1997, this coincided with a downturn of performance scores. This trend turned around when pooling was later expanded in 2000. Similarly, the OAS expanded TNA access in 1997, but only after decision-making rules had been changed in 2002 to favor majoritarianism (pooling increased from 0.29 to 0.41) can we observe an increase in both performance indicators.

We do not find significant results for our second hypothesized interaction effectthat increased pooling would have a stronger positive effect on decision-making at lower levels of delegation (H5) (Models 8 and 11, Table 2). With strong independent effects in opposite directions, this does not come as a surprise. What is worth noting, however, is that the independent effect-positive for pooling (Model 8 and Model 11) and negative for delegation (Model 8) - disappears when we add the interaction term. This suggests that increases in pooling do not have a positive effect on longterm decision performance in the absence of delegation. A relevant example would 

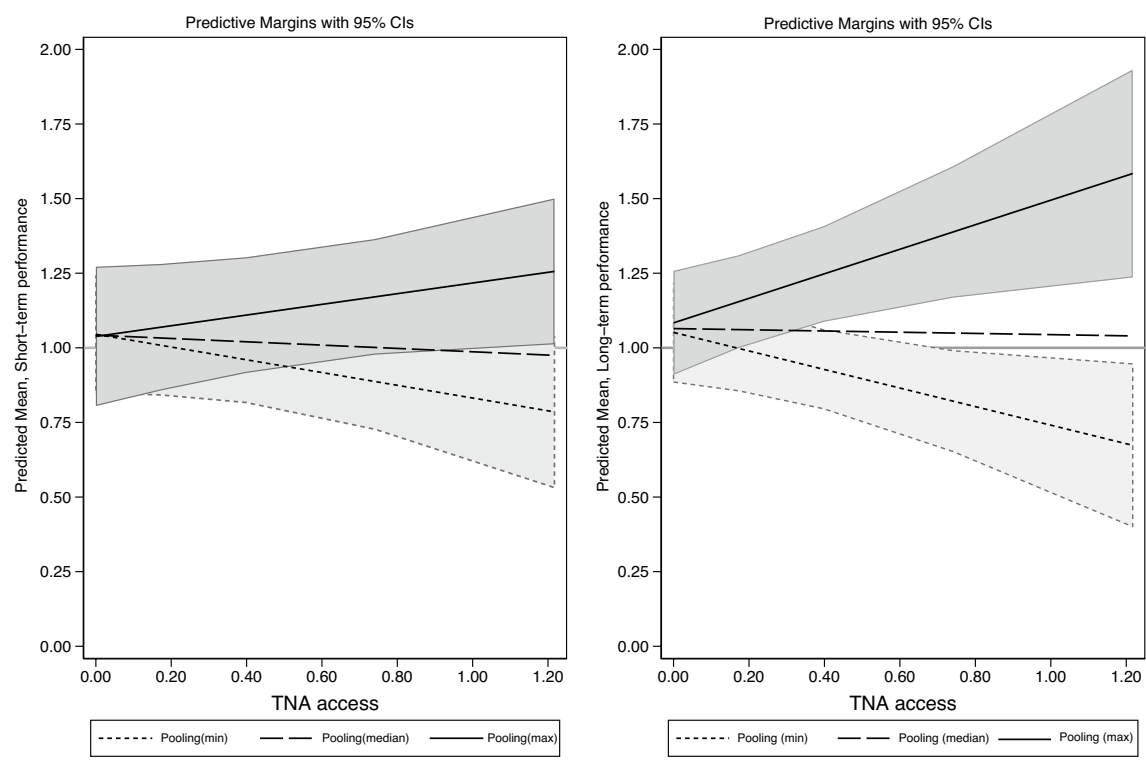

Fig. 4 Predicted means of decision-making performance for interaction of pooling and TNA access

be the OIC, whose decision-making output declined following a 2007 shift to an institutional setup with practically no delegation (0.05) and more pooling, compared to the situation at the turn of the millennium, when delegation was higher.

Finally, we find support for the expectation that increased delegation will have a stronger positive effect on decision-making performance at higher levels of TNA access (H6). Although the independent effect of delegation was negative, we note a significant coefficient for the interaction term of both variables, once again both for short-term performance and, at a lower significance level, for long-term performance (Table 2, Models 9 and 12). And without TNA access, we find the negative effect of increased delegation reported above. The predicted means plot in the appendix (Figure A.6 in the online appendix) shows that a growth of delegation actually has a positive effect on decision-making performance at very high levels of TNA access, and the downturn in decision-making performance caused by increased delegation is mainly observed for IOs with low levels of TNA access. ${ }^{23}$ For instance, the Commonwealth's reforms in 2005 combined greater access for TNAs with more delegation, which had a positive impact on decision-making performance in the following years. As another example, when the Council of Europe experienced a growth in the level of delegation in the 1990s, the decision-making index stabilized after an initial drop; then, a decade later, when the already high level of TNA access was further expanded, we observe several years of positive growth rates for both short-term and long-term performance.

${ }^{23}$ In the robustness section, we disaggregate the delegation variable for this interaction. 
To summarize, the results thus far are consistent with considerable portions of our theoretical argument $(\mathrm{H} 1, \mathrm{H} 4, \mathrm{H} 6)$, while some parts receive only weak (H5) or no support $(\mathrm{H} 2, \mathrm{H} 3){ }^{24}$ Three results stand out in particular. First, IOs that reform to pool decision-making powers can expect improvements in long-run decision-making performance $(\mathrm{H} 1)$. Second, increases in TNA access yield larger performance benefits if implemented in IOs that pool decision-making to a greater extent (H4). Third, while greater delegation of authority to supranational institutions on its own is associated with drops in performance, it can have a positive effect in combination with very high levels of access for TNAs (H6). In all, these findings suggest that these institutional design features primarily matter by way of how they combine to shape decision-making performance.

\subsection{Control variables}

We evaluated a number of additional variables to control for systematic differences across IOs. We find a significant result for the number of relevant IOs in the system (Model 4-6, Table 1). In contrast with existing claims (Gray, 2018), this suggests that higher institutional density — and thus competition-within a world region makes IOs more likely to increase decision-making activities in the long-term. The absolute number of decisions in the previous year varies greatly across IOs. As the negative coefficients in Models 1-3 (Table 1) indicate, IOs producing many decisions on a yearly basis are more likely to go through short-term dips in decisionmaking, and IOs producing fewer decisions on an annual basis are more likely to improve their performance in the short-term. However, producing a larger number of annual decisions has a positive effect on long-term performance (Models 4-6). Our results hence suggest that IOs adopting many decisions are more sensitive to crisis, but also are more capable of improving their decision-making performance in the long run. Against common expectations, the coefficient for our variable on the bindingness of decisions is positive across all models in Table 1 (but only significant for the long-term measure). It seems that IOs with binding decisions are more prone to expand the number of decisions in the long run-maybe because they assume binding output will be more effective or because states that agree to binding decisions are more likely to agree in general. For IOs with communiqué-based decisions, we observe positive and significant effects across all models, suggesting that IOs with such output have higher performance relative to other IOs, all else equal.

\subsection{Robustness}

We conduct a set of robustness checks. Following Hooghe et al., (2017: 107ff), we disaggregate delegation across phases of the decision-making process and apply separate indicators for delegation of agenda-setting, delegation of final decision-making

\footnotetext{
${ }^{24}$ We acknowledge the possibility that the weak support for some of our hypotheses might be linked to our focus on formal rules. Previous research on informal governance practices in IOs (Kleine 2013; Stone 2013) suggests that member states sometimes defy formal rules. However, assessing the effect of the discrepency between formal rules and their application goes beyond the scope of this study.
} 
and delegation of dispute settlement. The results (Table A.4 in the online appendix) suggest that the negative effect of delegation found above (Models 1 and 4) does not reflect a substitution effect, that is, when delegation of implementation to a supranational bureaucracy supplants intergovernmental decision-making: the coefficient for delegation on final decision-making is not significant (Model 14). Furthermore, a negative significant coefficient suggests that IOs with decreasing delegation of agenda-setting have greater chances for short-term improvements of their decisionmaking performance (Model 13), whereas the significant negative effect for longterm performance is only found for delegation on dispute settlement (Model 18, Table A.4 in the online appendix). We also re-estimate our models on interdependent effects with the disaggregated delegation measure and find strong support for a combined effect of pooling and delegation on agenda-setting (H5) for both shortterm and long-term performance (Model 19 and 25, Table A.5 and Figure A.7 in the online appendix). Finally, we only find a weakly significant result for the interaction between delegation and access when we use the measure for delegation on dispute settlement (Model 24, Table A.5 in the online appendix). These results suggest that delegation of dispute settlement and agenda setting, in particular, encumber decision-making as intergovernmental decision-making bodies become concerned with monitoring supranational bodies.

In Table A.6 in the online appendix, we present alternative specifications of our main models. Overall, our main results are robust. Above, we explained why our two indices give a good representation of decision-making performance. In Model 31, we show that a simpler version of our dependent variable with a shorter reference period (previous year) leads to robust results for our main independent variables. ${ }^{25}$ In Model 32, we then substitute our dependent variable with a non-logged version of our measure for long-term decision-making performance. This model mainly confirms the above results for institutional design, but together with Model 31, it also suggests that we may underestimate the effect of other covariates when we log the performance measure. We find significant coefficients for a positive effect of TNA access, membership, IO staff, and preference heterogeneity on decision-making. As even our logged indices show high volatility - as exemplified by the AU in the early 1980s (Fig. 3), Models 33 and 34 (Table A.6 in the online appendix) exclude extreme values of the dependent variable on both ends of the scale. We find robust results, and again, more significant covariates. In this case, there is support for a positive effect of politicization-in terms of IO media visibility-and democratic density (for long-term performance).

Table A.6 in the online appendix also shows two models based on an OLS estimator (Models 35 and 36) that leads to highly similar results. As we outlined above, we see strong reasons for the use of fixed effects. Models 37 and 38 (Table A.6 in the online appendix) illustrate what happens if we drop this assumption for yearfixed effects that account for unmodeled events like the global economic crisis in 2009 or $9 / 11 .{ }^{26}$ We get a highly similar outcome, except for the independent effect of

\footnotetext{
25 In Figure A.8, we illustrate how this version of our dependent variable - although logged -- has a high degree of volatility with extreme year-to-year changes.

26 Both events can be identified in the aggregate trend of decision-making in Fig. 2.
} 
pooling on long-term performance that is still positive, but no longer significant. If we exclude unit dummies, delegation is still significant for long-term performance, whereas pooling is not (Model 39 and 40, Table A.6 in the online appendix). The short-term model performs overall poorly, but TNA access and several control variables become significant for long-term performance.

In Models 41, 42, and 43 in Table A.7 in the online appendix, we add a lagged version of the dependent variable. The main results are robust. For short-term performance, we find additional significant coefficients for membership (negative), policy scope, IO staff, and democratic density (all positive) For long-term performance, the absolute number of decisions is correlated with the lagged dependent variable. In the end, Models 41 and Model 43 (without $N$. of decisions) add robustness to our main results.

Finally, we control for the composition of our sample. Models 44 and 45 present the results for Models 1 and 4 from Table 1 without communiqué-based IOs. Again, we find robust results. When we drop the years before the end of the Cold War, the main results remain robust (Model 46 and 47, Table A.7 in the online appendix). In this case, we even find support for a positive effect of media coverage on long-term performance, and a negative effect of preference heterogeneity and democratic density in the short term. The same holds when we exclude large IOs (i.e., the UN and EU) from our sample, since these IOs are often described as special cases (Models 48 and 49).

\section{Conclusion}

Arriving at decisions is a first and necessary requirement for IOs to make a difference in world politics. Yet, so far, our understanding of the factors contributing to decision-making performance in IOs has been limited. This article attempts to address this gap.

We arrive at several key findings. Importantly, we establish that variation in decision-making performance across and within IOs is systematically shaped by features of institutional design. Yet institutional design features tend to shape decision-making performance in more complex ways than typically anticipated. Independently, only pooling has a positive effect on IO decision-making. Delegation in fact appears to have a negative average effect. Instead, we find that the most substantial effects of these design features reside in how they interact with one another. TNA access has a more positive effect on decision-making performance when pooling is greater. Without pooling, the resources that TNAs offer to decision-making can be easily outweighed by the power of the national veto. Also, the effect of increased delegation is conditional on the extent of TNA access-its observed independent negative effect is reduced or even turned around for very high values of TNA access. These findings suggest that viewing design features in isolation of one another underestimates the importance of institutional design for IO decision-making performance.

In all, this article makes three broader contributions. First, inspired by the study of domestic legislative performance, we approach performance by looking 
at IO decision-making in terms of policy output. This approach is advanced by an original measure of decision-making performance based on the annual growth rate in output. It means that cross-sectionally, we compare IOs in terms of their output growth and not their absolute levels of output. Using this measure, we are able to make meaningful, systematic comparisons of the decision-making performance of IOs, both over time and across organizations. We argue that this approach sheds light on IO performance more broadly because IO decisionmaking is a crucial intermediate step between process and outcome (Gutner \& Thompson 2010). Future research, however, is necessary to more adequately understand how decision-making performance relates to other aspects of IO performance and regime effectiveness, such as goal attainment and problem-solving. In this respect, the study of decision-making performance can also contribute to the growing scholarship on the termination and death of IOs (Debre \& Dijkstra, 2021; Eilstrup-Sangiovanni, 2021), by linking dynamics of policy output to the risk of organizational failure.

Second, we provide an explanation for IO decision-making performance. While previous research calls into question the role of institutional design for performance (Barnett \& Finnemore, 2004; Gray, 2018), we renew claims of the significance of institutional design by considering how pooling, delegation, and TNA access affect decision-making performance. In particular, we examine how the shift away from purely member-driven IOs affects the strategic setting within which decision-making occurs. While previous literature focuses on how individual features of institutional design have independent effects on IO performance, we have taken the additional step to theorize and examine how different design features interact to shape decision-making. Our findings suggest that future research should pay greater attention to how rules combine to have an impact on IOs. While we assume these interactions reflect rational combinations of design elements, it may also prove fruitful to explore potential unintended consequences. Moreover, as pooling, delegation, and TNA access are among the most profound developments in IO design in recent decades, this article contributes to understanding how these developments have transformed the impact of IOs.

Third, we offer the first comparative assessment of the decision-making performance of IOs. Going beyond analysis of an individual IO, we identify general patterns and explanations of IO decision-making performance across a broad spectrum of 30 IOs from 1980 to 2011. While comparative studies of IO performance do exist, none focuses on decision-making. Consequently, this article makes a significant empirical contribution to comparative research on IOs. One question our analysis raises is whether the general patterns we observe transcend issue areas, or if they further interact with problem structures as may be inferred from rational institutionalist assumptions. Possible next steps for future research could also include in-depth case studies on how the interactions between pooling, delegation, and TNA access unfold in specific IOs, and on how de facto governance practices interfere with the effect of formal rules.

Supplementary Information The online version contains supplementary material available at https://doi. org/10.1007/s11558-021-09445-X. 
Acknowledgements Earlier versions of this article were presented at the 2021 virtual Annual Convention of the International Studies Association, the 2020 Annual Meeting of the American Political Science Association, the 2018 Annual Convention of the International Studies Association in San Francisco, the 2016 Annual Convention of the International Studies Association in Atlanta, and at the Global and Regional Governance Workshop at Stockholm University. For helpful comments and suggestions, we are particularly grateful to Yoram Haftel, Hylke Dijkstra, Alex Thompson, Lisa Martin, and to the editor and three anonymous reviewers of ROIO. The research for this article was funded by the Swedish Research Council (Grant 2013-01559).

Author contributions Research design and conceptualization: T.So.: (30\%), T.Sq. (30\%), J.T. (20\%), M.L. (20\%). Statistical analysis: T.So. (70\%) T.Sq. (10\%), J.T. (10\%), M.L. (10\%). Writing: T.So. (30\%), T.Sq. (40\%), J.T. (15\%), M.L. (15\%). The order of authors reflects the significance of the authors' contributions.

Funding Open Access funding enabled and organized by Projekt DEAL.

Open Access This article is licensed under a Creative Commons Attribution 4.0 International License, which permits use, sharing, adaptation, distribution and reproduction in any medium or format, as long as you give appropriate credit to the original author(s) and the source, provide a link to the Creative Commons licence, and indicate if changes were made. The images or other third party material in this article are included in the article's Creative Commons licence, unless indicated otherwise in a credit line to the material. If material is not included in the article's Creative Commons licence and your intended use is not permitted by statutory regulation or exceeds the permitted use, you will need to obtain permission directly from the copyright holder. To view a copy of this licence, visit http://creativecommons.org/licen ses/by/4.0/.

\section{References}

Abbott, K. W., Genschel, P., Snidal, D., \& Zangl, B. (2015). International Organizations as Orchestrators. Cambridge University Press.

Alesina, A., Angeloni, I., \& Schuknecht, L. (2005). What does the European Union do? Public Choice, 123(3-4), 275-319.

Allen, S. H., \& Yuen, A. T. (2014). The politics of peacekeeping: UN Security Council oversight across peacekeeping missions. International Studies Quarterly, 58(3), 621-632.

Alter, K. (2014). The New Terrain of International Law: Courts. Princeton University Press.

Alter, K., \& Raustiala, K. (2018). The rise of international regime complexity. Annual Review of Law and Social Science, 14(1), 329-349.

Arter, D. (2006). Introduction: Comparing the legislative performance of legislatures. Journal of Legislative Studies, 12(3-4), 245-257.

Axelrod, R., \& Keohane, R. O. (1985). Achieving cooperation under anarchy: Strategies and institutions. World Politics, 38(1), 226-254.

Barnett, M., \& Finnemore. (2004). Rules for the World: International Organizations in Global Politics. Cornell University Press.

Bes, B. J., Sommerer, T., \& Agné, H. (2019). On legitimacy crises and the resources of global governance institutions: A surprisingly weak relationship? Global Policy, 10(3), 313-326.

Betsill, M., \& Corell, E. (2008). NGO Diplomacy: The influence of nongovernmental organizations in international environmental negotiations. MIT Press.

Blake, D. J., \& Payton, A. L. (2015). Balancing design objectives: Analyzing new data on voting rules in intergovernmental organizations. Review of International Organizations, 10(3), 377-402.

Boehmer, C., Gartzke, E., \& Nordstrom, T. (2004). Do intergovernmental organizations promote peace? World Politics, 57(1), 1-38.

Bradley, C., \& Kelley, J. (2008). The concept of international delegation. Law and Contemporary Problems, 71(1), 1-36. 
Cheibub, J. A., Gandhi, J., \& Vreeland, J. R. (2010). Democracy and dictatorship revisited. Public Choice, 143(1), 67-101.

Cichowski, R. A. (2006). Courts, rights and democratic participation. Comparative Political Studies, $39(1), 50-75$.

Christensen, J. G. (2010). EU legislation and national regulation: Uncertain steps towards a european public policy. Public Administration, 88(1), 3-17.

Cline, K., Rhamey, P., Henshaw, A., Sedziaka, A., Tandon, A., \& Volgy, T. J. (2011). Identifying Regional Powers and their Status. In T. Volgy, R. Corbetta, K. Grant, \& R. Baird (Eds.), Major Powers and the Quest for Status in International Politics (pp. 133-157). Palgrave Macmillan.

Damgaard, E., \& Jensen, H. (2006). Assessing strength and weakness in legislatures: The case of Denmark'. Journal of Legislative Studies, 12(3-4), 426-442.

Debre, M. J., \& Dijkstra, H. (2021). Institutional design for a post-liberal order: Why some international organizations live longer than others. European Journal of International Relations, 27(1), 311-339.

Dingwerth, K., Witt, A., Lehmann, I., Reichel, E., \& Weise, T. (Eds.). (2019). International organizations under pressure: legitimating global governance in challenging times. Oxford University Press.

Drezner, D. (2007). All politics is global. Explaining international regulatory regimes. Princeton University Press.

Ehlermann, C.-D., \& Ehring, L. (2005). Decision-making in the world trade organization. is the consensus practice of the world trade organization adequate for making, revising and implementing rules on international trade? Journal of International Economic Law, 8(1), 51-75.

Eilstrup-Sangiovanni, M. (2021). What kills international organisations? When and why international organisations terminate. European Journal of International Relations, 27(1), 281-310.

Elsig, M. (2010). The World Trade Organization at work: performance in a member-driven milieu. Review of International Organizations, 5(3), 345-363.

Finke, D., \& Bailer, S. (2019). Crisis bargaining in the European Union: Formal rules or market pressure? European Union Politics, 20(1), 109-133.

Golub, J. (2008). The study of decision-making speed in the European Union. European Union Politics, $9(1), 167-179$.

Gornitzka, A., \& Sverdrup, U. (2011). Access of experts: Information and EU decision-making. West European Politics, 34(1), 48-70.

Gray, J. (2018). Life, death, or zombie? The vitality of international organizations. International Studies Quarterly, 62(1), 1-13.

Gutner, T., \& Thompson, A. (2010). The Politics of IO performance (Special Issue). Review of International Organizations, 5(3), 227-385.

Hansen, H. E., McLaughlin Mitchell, S., \& Nemeth, S. C. (2008). IO Mediation of interstate conflicts: Moving beyond the global versus regional dichotomy. Journal of Conflict Resolution, 52(2), 295-325.

Hawkins, D., Lake, D., Nielson, D., \& Tierney, M. (Eds.). (2006). Delegation and agency in international organizations. Cambridge University Press.

Holloway, S., \& Tomlinson, R. (1995). The new world order and the general assembly: Bloc realignment at the UN in the Post-Cold War world. Canadian Journal of Political Science, 28(2), 227-254.

Hooghe, L., Lenz, T., \& Marks, G. (2019). A theory of international organization. Oxford University Press.

Hooghe, L., Marks, G., Lenz, T., Bezuijen, J., Ceka, B., \& Derderyan, S. (2017). Measuring international authority: A postfunctionalist theory of governance (Vol. III). Oxford University Press.

Hooghe, L., \& Marks, G. (2015). Delegation and pooling in international organizations. Review of International Organizations, 10(3), 305-328.

Keohane, R., \& Hoffmann, S. (Eds.). (1991). The new European community: Decisionmaking and institutional. Westview Press.

Kleine, M. (2013). Informal governance in the European Union: How governments make international organizations work. Cornell University Press.

Koremenos, B., Lipson, C., \& Snidal, D. (2001). The rational design of international institutions. International Organization, 55(4), 761-799.

König, T. (2007). Divergence or convergence? From ever-growing to ever-slowing european legislative decision making. European Journal of Political Research, 46(3), 417-444.

Lake, D. A., \& McCubbins, M. (2006). The logic of delegation to international organizations. In D. Hawkins, D. Lake, D. Nielson, \& M. Tierney (Eds.), Delegation and Agency in International Organizations (pp. 341-368). Cambridge University Press. 
Lake, D. A., \& Powell, R. (1999). Strategic choice and international cooperation. Princeton University Press.

Lall, R. (2017). Beyond institutional design: explaining the performance of international organizations. International Organization, 71(2), 245-280.

Landolt, L., \& Woo, B. (2017). NGOs invite attention: From the United Nations Commission on Human Rights to the Human Rights Council. Journal of Human Rights, 16(4), 407-427.

Mansfield, E., Milner, H., \& Rosendorff, P. (2002). Why democracies cooperate more: Electoral control and international trade agreements. International Organization, 56(3), 477-513.

Mansfield, E., \& Pevehouse, J. C. (2008). Democratization and the varieties of international organizations. Journal of Conflict Resolution, 52(2), 269-294.

Martin, L. A., \& Simmons, B. A. (2012). International organizations and institutions. In W. Carlsnaes, T. Risse, \& B. A. Simmons (Eds.), Handbook of international relations (2nd ed., pp. 326-351). SAGE.

Mitchell, R. (2002). A quantitative approach to evaluating international environmental regimes. Global Environmental Politics, 2(4), 58-83.

Naurin, D., \& Wallace, H. (Eds). (2008). Unveiling the Council of the European Union: Games Governments Play in Brussels. Basingstoke: Palgrave.

O’Brien, R., Goetz, A. M., Scholte, J. A., \& Williams, M. (2000). Contesting global governance: Multilateral economic institutions and global social movements. Cambridge University Press.

Olson, D. M., \& Nonidez, C. T. (1972). Measures of legislative performance in the US house of representatives. Midwest Journal of Political Science, 16(2), 269-277.

Pevehouse, J. C., Nordstrom, T., McManus, R. W., \& Jamison, A. S. (2020). Tracking organizations in the world: The Correlates of War IGO version 3.0 datasets. Journal of Peace Research, 57(3), 492-503.

Pollack, M. (1997). Delegation, agency, and agenda setting in the European community. International Organization, 51(1), 99-134.

Pollack, M., \& Hafner-Burton, E. (2010). Mainstreaming international governance: The environment, gender, and IO performance in the European Union. Review of International Organizations, 5(3), 285-313.

Rasmussen, A., \& Toshkov, D. (2013). The effect of stakeholder involvement on legislative duration: consultation of external actors and legislative duration in the European Union. European Union Politics, 14(3), 366-387.

Raustiala, K. (1997). States, NGOs, and international environmental institutions. International Studies Quarterly, 41(4), 719-740.

Rittberger, V., Zangl, B., \& Kruck, A. (2012). International organization (2nd ed.). Palgrave Macmillan.

Scharpf, F. W. (1997). Games real actors play. Westview Press.

Schulz, H., \& König, T. (2000). Institutional reform and decision-making efficiency in the European Union. American Journal of Political Science, 44(4), 653-666.

Shanks, C., Jacobson, H. K., \& Kaplan, J. H. (1996). Inertia and change in the constellation of international governmental organizations, 1981-1992. International Organization, 50(4), 593-627.

Shepsle, K. (2008). Rational Choice Institutionalism. In S. H. Binder, R. A. W. Rhodes, \& B. A. Rockman (Eds.), Oxford handbook of political institutions (pp. 23-38). Oxford University Press.

Simmons, B. A. (2009). Mobilizing for human rights: International law in domestic politics. Cambridge University Press.

Slapin, J. B. (2008). Bargaining power at Europe's intergovernmental conferences: testing institutional and intergovernmental theories. International Organization, 62(1), 131-162.

Squatrito, T., Young, O., Follesdal, A., \& Ulfstein, G. (Eds.). (2018). The performance of international courts and tribunals. Cambridge University Press.

Steffek, J., Kissling, C., \& Nanz, P. (Eds.). (2008). Civil society participation in european and global governance: A cure for the democratic deficit? Palgrave Macmillan.

Stone, R.W. (2011). Controlling Institutions: International Organizations and the Global Economy. Cambridge University Press.

Stone, R. W. (2013). Informal governance in international organizations: Introduction to the special issue. Review of International Organizations, 8(2), 121-136.

Tallberg, J. (2015). Orchestrating Enforcement. In K. Abbott, P. Genschel, D. Snidal, \& B. Zangl (Eds.), International organizations as orchestrators (pp. 166-188). Cambridge University Press.

Tallberg, J. (2002). Delegation to supranational institutions: Why, how, and with what consequences? West European Politics, 25(1), 23-46.

Tallberg, J., Sommerer, T., Squatrito, T., \& Lundgren, M. (2016a). The performance of international organizations: A policy output approach. Journal of European Public Policy, 23(7), 1077-1096.

Tallberg, J., Sommerer, T., \& Squatrito, T. (2016b). Democratic memberships in international organizations: Sources of institutional design. Review of International Organizations, 11(1), 59-87. 
Tallberg, J., Sommerer, T., Squatrito, T., \& Jönsson, C. (2014). The transnational design of international organizations. International Organization, 68(4), 741-774.

Thomson, R., Stokman, F. N., Achen, C. H., \& König, T. (Eds.). (2006). The European Union decides. Cambridge University Press.

Voeten, E. (2013). Data and Analyses of Voting in the UN General Assembly. In B. Reinalda (Ed.), Routledge Handbook of International Organization. London: Routledge.

Vreeland, J., \& Dreher, A. (2014). The political economy of the United Nations Security Council: Money and influence. Cambridge University Press.

Young, O. (1999). Governance in world affairs. Cornell University Press.

Zürn, M., Binder, M., \& Ecker-Ehrhardt, M. (2012). International authority and its politicization. International Theory, 4(1), 69-106.

Zürn, M. (2018). A Theory of Global Governance: Authority, Legitimacy, and Contestation. Oxford University Press.

Publisher's note Springer Nature remains neutral with regard to jurisdictional claims in published maps and institutional affiliations.

\section{Authors and Affiliations}

\section{Thomas Sommerer ${ }^{1}(1) \cdot$ Theresa Squatrito $^{2}$. Jonas Tallberg ${ }^{3}$. Magnus Lundgren ${ }^{4}$}

Theresa Squatrito

T.J.Squatrito@1se.ac.uk

Jonas Tallberg

jonas.tallberg@statsvet.su.se

Magnus Lundgren

Magnus.lundgren@gu.se

1 Universität Potsdam, Potsdam, Germany

2 London School of Economics, London, England

3 Stockholms universitet, Stockholm, Sweden

4 Göteborgs universitet, Gothenburg, Sweden 